\title{
APPI-MS: Effects of Mobile Phases and VUV Lamps on the Detection of PAH Compounds
}

\author{
Luke Chandler Short, Sheng-Suan Cai, and Jack A. Syage \\ Syagen Technologies, Inc., Tustin, California, USA
}

The technique of atmospheric pressure photoionization (APPI) has several advantages over electrospray ionization (ESI) and atmospheric pressure chemical ionization (APCI), including efficient ionization of nonpolar or low charge affinity compounds, reduced susceptibility to ion suppression, high sensitivity, and large linear dynamic range. These benefits are greatest at low flow rates (i.e., $\leq 100 \mu \mathrm{L} / \mathrm{min}$ ), while at a higher flow, photon absorption and ion-molecule reactions become significant. Under certain circumstances, APPI signal and S/N have been observed to excel at higher flow, which may be due to a nonphotoionzation mechanism. To better understand APPI at higher flow rates, we have selected three lamps (Xe, $\mathrm{Kr}$, and Ar) and four mobile phases typical for reverse-phase, high-pressure liquid chromatography: acetonitrile, methanol, (1:1) acetonitrile:water and (1:1) methanol:water. As test compounds, three polyaromatic hydrocarbons are studied: benzo[a]pyrene, indeno[1,2,3-c, d]pyrene and benz[a]anthracene. We find that solvent photoabsorption cross-section is not the only parameter in explaining relative signal intensity, but that solvent photo-ion chemistry can also play a significant role. Three conclusions from this investigation are: (1) methanol photoionization leads to protonated methanol clusters that can result in chemical ionization of analyte molecule; (2) use of the Ar lamp often results in greater signal and S/N; (3) acetonitrile photoionization is less efficient and resulting clusters are too strongly bound to chemically ionize the analyte efficiently, so that analyte ion formation is dominated by direct photoionization. (J Am Soc Mass Spectrom 2007, 18, 589-599) (C 2007 American Society for Mass Spectrometry

$\mathrm{M}$ ethods to detect nonpolar compounds by liquid chromatography-mass spectrometry (LCMS) have advanced significantly over the last few years, owing to development of newer source technologies [1-3] and improved choices of mobile phase(s) for chromatographic separation [4, 5]. Recent work has focused on the direct comparison of different sources (APPI, APCI, and ESI) with specific target compounds, e.g., polyaromatic hydrocarbons $[6,7]$, hydrophobic peptides [8], pesticides $[9,10]$, as well as fatty acids and lipids $[4,5]$. In many cases atmospheric pressure photoionization (APPI) [1, 7] has demonstrated extended linear dynamic range [11], enhanced sensitivity and thus lower detection limits [6, 9, 12-15], and reduced or no off-line sample cleanups $[6,9]$ in comparison with direct APCI or ESI. Adding a dopant (dopant-assisted, DA) to the mobile phase in many cases can further increase sensitivity [2].

A related analytical technique is atmospheric pressure laser ionization (APLI), which has shown excellent sensitivity for certain non- or low-polar compounds [3]. The enhanced sensitivity is a direct result of the high photon flux associated with a laser system, often several orders of magnitude higher than the noncoherent light

Published online December 22, 2006

Address reprint requests to Dr. J. A. Syage, Syagen Technologies, Inc., 1411 Warner Ave., Tustin, CA 92780, USA. E-mail: jsyage@syagen.com sources, e.g., lamps used with APPI. The APLI source relies on one-color, two-photon $(1+1)$ resonantlyenhanced multiphoton ionization (REMPI), typically using a $\mathrm{KrF}$ excimer laser emitting light at $5.0 \mathrm{eV}$, efficiently ionizing nonpolar molecules. However, APLI is not yet widely used due to the large size, expense, and maintenance associated with the laser system. Furthermore, changing the wavelength of an excimer laser requires the replacement of the gas mixture and often re-tuning of the laser cavity, whereas with an APPI system, the wavelength can be changed by simply switching the lamp.

To improve the capabilities of APPI for LC-MS, we have focused on the ion chemistry involved in and following the photoionization process. Although direct, single-photon ionization (SPI) of a compound [M] results in the radical cation $[\mathrm{M}]^{+}$, use of certain mobile phases can result in the adduct $[\mathrm{M}+\mathrm{H}]^{+}[16]$. The notion that a solvent can play a significant role has been observed with APPI [4], DA-APPI [17], and APLI [3]; however, there is little published experimental evidence as to which solvents or solvent combinations are best suited for specific light sources. We recently observed that the solvent acetonitrile results in a lower analyte response compared with methanol [7], and this effect has also been observed with acetonitrile and chloroform $[17,18]$. This effect becomes more significant at high flow rates, and has recently been theorized by Kauppila 
and Bruins to be a result of the large photoabsorption cross-section of acetonitrile at a light energy of $10.0 \mathrm{eV}$ [18]. Using a simple flow model and the Beer-Lambert law, the solvent-dependent attenuation of light intensity, $\mathrm{I} / \mathrm{I}_{0}$, is calculated to be 0.55 at $100 \mu \mathrm{L} / \mathrm{min}, 0.30$ at $200 \mu \mathrm{L} / \mathrm{min}$, and 0.05 at $500 \mu \mathrm{L} / \mathrm{min}$ (assuming a $1 \mathrm{~mm}$ long absorption region). It is concluded by Kauppila and Bruins that for flow rates greater than $200 \mu \mathrm{L} / \mathrm{min}$, the light intensity from a $\mathrm{Kr}$ lamp cannot travel more than a few millimeters into the ionization volume. Loss in signal intensity has also been observed with dopant assisted (DA)-APPI at higher flow rates, and the mechanism of solvent-induced collisional quenching of a dopant ion precursor has been ruled out as the reason for signal loss [19].

The goal of the current study is to present a spectroscopic and photochemical explanation of why some solvents have been successful at compound detection by APPI while others are more problematic. In addition, we will provide evidence and support of specific ion chemistry expected to occur within the APPI source. We also present an overview of the photoabsorption characteristics of several solvents commonly used with reverse-phase, high-pressure liquid chromatography (RP-HPLC) mass spectrometry (MS) as useful information in determining the most appropriate photon energy (commonly $\mathrm{Xe}, \mathrm{Kr}$, or Ar VUV lamps) for use with specific solvents or solvent combinations.

We have chosen three polyaromatic hydrocarbons $(\mathrm{PAH})$ as test compounds for this study: benzo[a]pyrene, benz $[a]$ anthracene (or 1,2-benzanthracene) and indeno[1,2,3c, d]pyrene (or o-phenylenepyrene). All three of these compounds can be measured using the lamps tested here, with ionization potentials of $7.41 \mathrm{eV}$ for benzo[a]pyrene [20], $7.46 \mathrm{eV}$ for benz[a]anthracene [21], and ca. $7.1 \mathrm{eV}$ for $o$-phenylenepyrene (estimated from the shift in ionization potential from naphthalene [22] to fluoranthrene [23] applied to pyrene [20].

\section{Physical Properties of Photoionization}

\section{Direct Compound Ionization Via Photoionization}

The main goal of photoionization is the selective detection of compound $[\mathrm{M}]$ as either parent ion, $[\mathrm{M}]^{+}$ or $[\mathrm{M}+\mathrm{H}]^{+}$, or as a controlled fragment, $[\mathrm{F}]^{+}$. Fragmentation analysis is often useful for structural analysis. Within the APPI source, there exists not only the target compound(s), but also solvent molecules, e.g., acetonitrile, methanol, or water. When choosing the ideal solvent for a particular target compound, not only is the chromatographic separation an important criterion, but also the spectroscopic and reactive properties during photoionization.

Absorption spectra for these three solvents are presented in Figure 1 (left). Several features are apparent for the energy range presented:

- Light generated from a Xe lamp $(8.4 \mathrm{eV})$ corresponds to a significantly lower cross-section for water and acetonitrile than for methanol.

- Light generated from a Kr lamp (10.0 and $10.6 \mathrm{eV})$ corresponds to a significantly lower cross-section for methanol and water than for acetonitrile.

- Light generated from an Ar lamp (11.7 eV) corresponds to a low cross-section for water, followed by methanol, followed by acetonitrile.

Table 1 contains spectral properties pertinent to the photon energies emitted by $\mathrm{Xe}, \mathrm{Kr}$, and Ar lamps for common LC-MS solvents.

\section{Dependence of Photoabsorption on Solvent Flow}

The penetration of light through the sample region is dependent upon the number density of absorbing species, which in turn is dependent upon solvent flow. The effect of flow rate on measured ion intensity with an

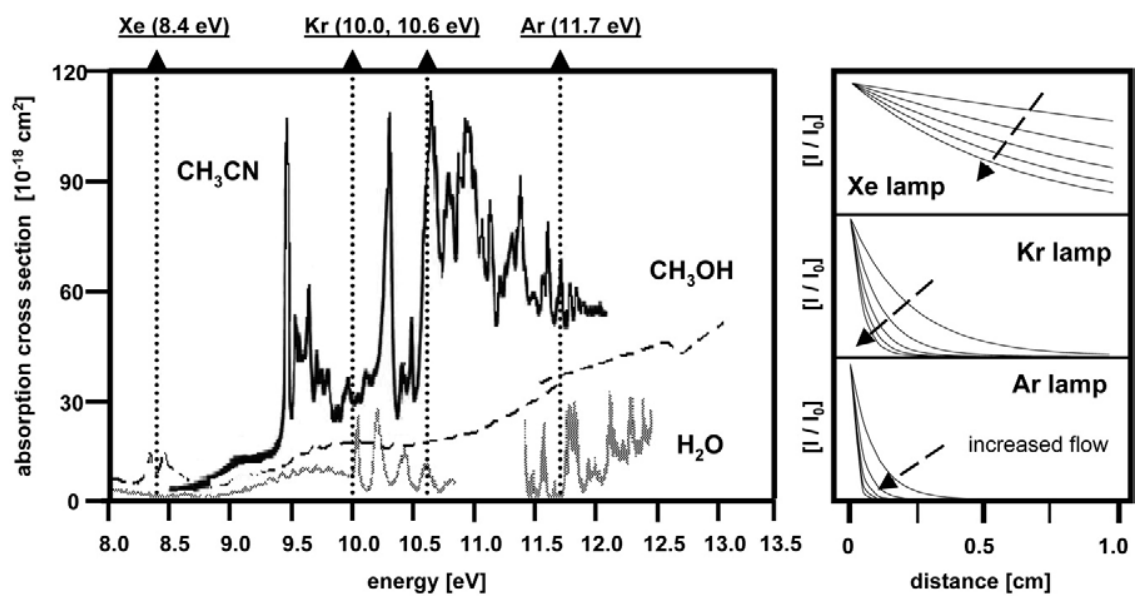

Figure 1. (left) Photoabsorption cross-sections for acetonitrile, $\mathrm{CH}_{3} \mathrm{CN}(0.1 \mathrm{~nm}$ resolution); [24, 25] methanol, $\mathrm{CH}_{3} \mathrm{OH}\left(0.5 \mathrm{~nm}\right.$ resolution); $[26,27]$ and water, $\mathrm{H}_{2} \mathrm{O}(0.075 \mathrm{~nm}$ resolution) $[28,29]$ in the range 8.0-13.0 eV. (right) Example of relative light transmission using three lamps $\mathrm{Xe}(8.4 \mathrm{eV}), \mathrm{Kr}(10.0$ $\mathrm{eV})$ and $\mathrm{Ar}(11.7 \mathrm{eV})$ in an APPI source with an acetonitrile flow of 100, 200, 300, 400 and $500 \mu \mathrm{L} / \mathrm{min}$. 
Table 1. Photoabsorption cross-sections for various solvent molecules used with APPI

\begin{tabular}{|c|c|c|c|c|c|}
\hline Solvent & $\begin{array}{l}\mathrm{IPa}^{\mathrm{a}} \\
{[\mathrm{eV}]}\end{array}$ & $\begin{array}{l}\mathrm{Xe}(8.4 \mathrm{eV}) \\
{\left[10^{-18} \mathrm{~cm}^{2}\right]}\end{array}$ & $\begin{array}{c}\mathrm{Kr}^{\mathrm{b}}(10.0,10.6 \mathrm{eV}) \\
{\left[10^{-18} \mathrm{~cm}^{2}\right]}\end{array}$ & $\begin{array}{l}\operatorname{Ar}(11.7 \mathrm{eV}) \\
{\left[10^{-18} \mathrm{~cm}^{2}\right]}\end{array}$ & References \\
\hline Isopropyl alcohol & 10.17 & 12 & $43^{c}, 55$ & 80 & $(\mathrm{Kr}, \mathrm{Ar})[30],(\mathrm{Xe})[31]$ \\
\hline$n$-Propanol & 10.18 & 8.5 & $48^{c}, 51$ & 82 & $(\mathrm{Kr}, \mathrm{Ar})[30],(\mathrm{Xe})[32]$ \\
\hline Hexane & 10.18 & 27 & 65,76 & 120 & {$[33]$} \\
\hline Ethanol & 10.43 & 9.5 & 26,33 & 45 & [34] \\
\hline Methanol & 10.85 & 11.3 & 15,15 & 30 & $(\mathrm{Xe})[26],(\mathrm{Kr}, \mathrm{Ar})[27]$ \\
\hline Methylene chloride & 11.32 & $6.2^{\mathrm{d}}$ & $130^{d}, 130^{d}$ & - & [35] \\
\hline Chloroform & 11.37 & 2.8 & 36,59 & 72 & [36] \\
\hline Acetonitrile & 12.20 & 1.8 & 24,120 & 60 & $(\mathrm{Xe}, \mathrm{Kr})[25],(\mathrm{Ar})[24]$ \\
\hline Water & 12.59 & 0.8 & $15,6.4$ & 2 & $(\mathrm{Xe}, \mathrm{Kr})[29],(\mathrm{Ar})[28]$ \\
\hline
\end{tabular}

a IP values from CRC Handbook of Chemistry and Physics, shaded boxes = solvent is ionized.

${ }^{b}$ Relative intensity is $(1: 4)$ for $\mathrm{Kr}(10.6 \mathrm{eV}): \mathrm{Kr}(10 \mathrm{eV})$.

'Extrapolated from experimental spectra.

${ }^{\mathrm{d} C}$ Converted from molar extinction coefficient.

APPI source and LC-MS has been reported previously using a Kr lamp [18], where the signal intensity can be seen to decrease at higher flow rates. Based on Beer's Law, light transmission is $\mathrm{I} / \mathrm{I}_{0}=\exp (-\sigma \mathrm{nx})$, which is a function of the wavelength-dependent photoabsorption cross-section, $\sigma$, molecular number density, $\mathrm{n}$, and path length, $x$. The ratio $\mathrm{I} / \mathrm{I}_{0}$ as a function of distance is plotted for acetonitrile in Figure 1 (right) for flow rates ranging from 100 to $500 \mu \mathrm{L} / \mathrm{min}$, and for three different photoabsorption cross-sections, $\sigma_{\mathrm{Xe}}=1.8 \times 10^{-18} \mathrm{~cm}^{2}$, $\sigma_{\mathrm{Kr}}=24 \times 10^{-18} \mathrm{~cm}^{2}$, and $\sigma_{\mathrm{Ar}}=60 \times 10^{-18} \mathrm{~cm}^{2}$.

These light transmission plots demonstrate that light from a Xe lamp has the greatest depth of penetration at all flow rates for acetonitrile, whereas light from an Ar lamp has the lowest depth of penetration and is completely absorbed by the solvent after a few millimeters. This trend is the same when a mobile phase of methanol is used. If photoabsorption alone is significant for analyte ionization and detection, then one would predict that the lamp's effectiveness for these two mobile phases would be $\mathrm{Xe}>\mathrm{Kr}>\mathrm{Ar}$, assuming that no significant photochemistry occurs. We demonstrate here that photochemistry can play a major role in APPI.

\section{Experimental}

\section{Chemicals and Reagents}

The solvents chosen in this study were selected based on their common use with RP-HPLC-MS, their different VUV photoabsorption cross-sections in the energy range from 8 to $12 \mathrm{eV}$, and their good solubility with PAH compounds. The mobile phases studied here are pure solvents, acetonitrile and methanol, and mixed solvents, (1:1) acetonitrile:water and (1:1) methanol:water. The three PAH compounds studied here (benzo[a]pyrene, $o$-phenylenepyrene, and benz $[a]$ anthracene) represent commonly studied PAH compounds. Primary stock solutions of PAH compounds (Aldrich Chemicals Co., Inc., Milwaukee, WI) were made in the following concentrations: 1000 ppm benzo[a]pyrene in chloroform, 200 ppm o-phenylenepyrene in methanol, and 1000 ppm benz[a]anthracene in chloroform. Solutions were diluted and combined to contain $1 \mathrm{ppm}$ (equivalent to $1 \mathrm{ng} / \mu \mathrm{L}$ ) of each PAH in one of four solvents: methanol, acetonitrile, (1:1) methanol:water, or $(1: 1)$ acetonitrile:water.

\section{Instrument, Parameters, and Conditions}

A Micromass ZQ LC-MS (Waters Corporation, Milford, $\mathrm{MA}$ ) is used for these experiments. Flow injection analysis is performed (10 $\mu \mathrm{L}$ sample loop) with an APPI source (Syagen Technology, Inc., Tustin, CA). Lamps used are: Kr lamp (Syagen Technology, Inc., Tustin, CA), Xe lamp (Heraeus, Cambridge, London), and Ar lamp (Perkin Elmer Optoelectronics, Salem, MA). The data acquisition software is MassLynx 4.0. For single ion mode (SIM) detection, the detector monitors the ion peaks (with appropriate cone voltage): benzo[a]pyrene $\left[\mathrm{MH}^{+}(34 \mathrm{~V}), \mathrm{M}^{+}(86 \mathrm{~V})\right]$, o-phenylenepyrene $\left[\mathrm{MH}^{+}(54 \mathrm{~V})\right.$, $\left.\mathrm{M}^{+}(90 \mathrm{~V})\right]$, and benz $[a]$ anthracene $\left[\mathrm{MH}^{+}(43 \mathrm{~V}), \mathrm{M}^{+}(70 \mathrm{~V})\right]$, with a dwell time of $50 \mathrm{msec}$. Cone voltage is one key parameter in monitoring specific parent or fragment ions [4]. The specific value influences the ion ratios observed within the mass spectrum. After careful analysis using MassLynx acquisition software, we determined the ideal voltage settings for each ion species.

\section{Results and Discussion}

\section{Generation of Solvent Ions from Methanol} with APPI

Composition of methanol vapor. When methanol is used as a mobile phase with APPI, the major neutral species within the ion source other than nitrogen is methanol. There is experimental evidence that in the gas-phase methanol exists in significant quantities as hydrogenbonded dimers, trimers, and tetramers [37]. Photoelectron measurements of methanol vapor at reduced pressure (100 torr) and supersonic expansion have yielded a dimer/monomer ratio of 0.2 [38]. However, the thermo- 
dynamic conditions within the APPI source have a further reduced partial pressure of methanol (10 torr at $50 \mu \mathrm{L} / \mathrm{min}$ solvent flow) and the source used here is at a much higher temperature than that in the photoelectron experiment. To find an approximate value for the concentration of these solvent species within the APPI source, we calculate the equilibrium concentration using the general equation,

$$
\ln \left(K_{n}\right)=\frac{\Delta G_{n}}{R T}=\frac{\Delta S_{n}}{R}-\frac{\Delta H_{n}}{R T},
$$

where $K_{n}$ is the mole-fraction equilibrium constant for an $n^{\text {th }}$-size cluster, with an associated Gibb's freeenergy of reaction, $\Delta G_{n}$, entropy of reaction, $\Delta S_{n}$, and enthalpy of reaction, $\Delta \mathrm{H}_{\mathrm{n}}$. Given a temperature of $150^{\circ} \mathrm{C}$ and thermodynamic constants available from literature $[39,40]$, the equilibrium constants are calculated as $\mathrm{K}_{2}=0.011$ (dimer/monomer) and $\mathrm{K}_{3}=0.030$ (trimer/monomer). The trimer is a cyclic structure and is relatively more stable than the dimer. The partial pressures, $\mathrm{P}_{\mathrm{n}}$, for a $\mathrm{n}^{\text {th }}$-size cluster can be calculated from the relation,

$$
K_{n}=\frac{\left(P_{n} / P^{0}\right)}{\left(P_{1} / P^{0}\right)^{n}}
$$

where $P_{1}$ is the partial pressure of methanol (10 torr) and $P_{0}$ is the total pressure (760 torr nitrogen). This results in a partial pressure of 10 torr for the monomer, 0.002 torr for the dimer, and 0.0001 torr for the trimer.

Generation of solvent ions in methanol vapor. From the above calculation, methanol vapor in the ion source consists of ca. $99.98 \%$ monomer and $0.02 \%$ dimer. The ionization potential of methanol monomer and dimer are 10.84 and $9.74 \mathrm{eV}$, respectively [41]. The Xe lamp photon energy $(8.4 \mathrm{eV})$ is below both of these values, and will therefore not directly generate solvent cations. The $\mathrm{Kr}$ lamp photon energy (10.0 and $10.6 \mathrm{eV})$ is sufficient to ionize the trace dimer, but not the monomer. The Ar lamp photon energy $(11.7 \mathrm{eV})$ is sufficient to ionize both the monomer and dimer of methanol. The monomer ionization process is given by:

$$
\mathrm{CH}_{3} \mathrm{OH} \stackrel{h v}{\longrightarrow} \mathrm{CH}_{3} \mathrm{OH}^{+}+e^{-} \text {. }
$$

The dominant mechanism observed when methanol dimer is exposed to light from a $\mathrm{Kr}$ or Ar lamp is dissociative ionization [41],

$$
\begin{aligned}
& {\left[\mathrm{CH}_{3} \mathrm{OH}\right]_{2} \stackrel{h v}{\longrightarrow}\left[\mathrm{CH}_{3} \mathrm{OH}\right]_{2}^{+}+e^{-},} \\
& \stackrel{\left[\mathrm{CH}_{3} \mathrm{OH}\right]_{2}^{+}}{\longrightarrow} \longrightarrow\left[\mathrm{CH}_{3} \mathrm{OH}\right] \mathrm{H}^{+}+\mathrm{CH}_{3} \mathrm{O}\left(\text { or } \mathrm{CH}_{2} \mathrm{OH}\right) .
\end{aligned}
$$

Although eq $4 \mathrm{~b}$ is expected to be the primary solvent ionization mechanism, the rapid equilibrium established at atmospheric pressure between the solvent ions and neutrals leads to extensive complexation. Generation of large clusters is facilitated by the large binding energy of neutral $\mathrm{CH}_{3} \mathrm{OH}$ to protonated solvent clusters, e.g., $\mathrm{CH}_{3} \mathrm{OH}$ binding with $\left[\mathrm{CH}_{3} \mathrm{OH}\right]_{n} \mathrm{H}^{+}$is $-33 \mathrm{kcal} / \mathrm{mol}$ for $n=1,-22 \mathrm{kcal} / \mathrm{mol}$ for $n=2$, and $-16 \mathrm{kcal} / \mathrm{mol}$ for $n=3$ [42].

To determine the dominant solvent-ion species within the ion source, the cone voltage is set to a small value to minimize collision-induced dissociation. The dependence of ion abundance with cone voltage is measured to assess the stability of initially formed ions using either a $\mathrm{Kr}$ or Ar lamp (Figure 2). The largest difference between the two lamps is that there is about a $100 \times$ increase in solvent-ion intensity when the Ar lamp is used, despite the lower photon intensity associated with Ar versus Kr lamps of ca. 1:7. The significant increase in solvent ion concentration with the Ar lamp is likely a result of direct ionization of methanol monomer by the higher energy light, increasing the concentration of all solvent-ion species as cluster ion formation equilibrates.
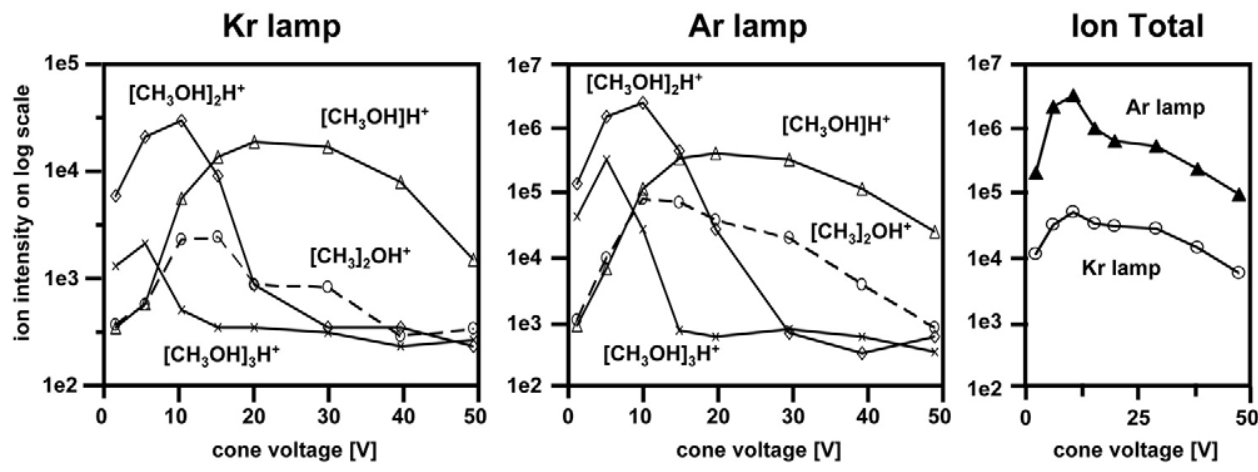

Figure 2. Ion intensity on a log scale for solvent species measured in methanol $(100 \mu \mathrm{L} / \mathrm{min})$ using either a Kr lamp (left) or an Ar lamp (middle). Ion totals (right) represent the sum of all detected ion species using either of the two lamps. Protonated dimer is the dominant species measured in both cases. Ar lamp results in a ca. $100 \times$ increase in solvent ion concentration for all measured species, despite reduced photon intensity. 
As calculated above, the dominant solvent species within the source is the monomer, $\mathrm{CH}_{3} \mathrm{OH}$. At low cone voltages, reflective of the true ion concentrations within the source, the dominant ions observed are $\left[\mathrm{CH}_{3} \mathrm{OH}\right]_{2} \mathrm{H}^{+}$and $\left[\mathrm{CH}_{3} \mathrm{OH}\right]_{3} \mathrm{H}^{+}$. As the only difference in either case is that the $\mathrm{CH}_{3} \mathrm{OH}$ will be ionized with light from an Ar lamp but not a Kr lamp, it is likely that the generated monomer ion rapidly clusters with neutral monomer.

Another trend that is observed at higher cone voltages is the disappearance of the protonated dimer, followed by the appearance of protonated monomer and dimethyl ether (Figure 2). The protonated dimer is the dominant species within the ion source. After this dimer passes through the sampling cone, a reaction occurs that is dependent upon the voltage difference between the sampling cone (0 to $50 \mathrm{~V})$ and the extraction cone $(3 \mathrm{~V})$. The reactions believed to occur as the cone voltage is increased are (with listed relative intensity):

$$
\begin{aligned}
& {\left[\mathrm{CH}_{3} \mathrm{OH}\right]_{2} \mathrm{H}^{+}} \\
& \underset{\mathrm{KE}}{\longrightarrow}\left[\mathrm{CH}_{3} \mathrm{OH}\right] \mathrm{H}^{+}+\left[\mathrm{CH}_{3} \mathrm{OH}\right] 90 \%, \\
& \underset{\mathrm{KE}}{\longrightarrow}\left[\mathrm{CH}_{3}\right]_{2} \mathrm{OH}^{+}+\mathrm{H}_{2} \mathrm{O} \quad 10 \% .
\end{aligned}
$$

These dissociation reactions are likely driven by the acceleration-induced fragmentation of solvent ions in a low-vacuum environment such as after entry into the sampling cone. The reaction of methanol to $\left[\mathrm{CH}_{3}\right]_{2} \mathrm{OH}^{+}$ has been previously observed as the dominant fragmentation product generated in a potential field of $70 \mathrm{~V}$ and a $50 \mathrm{~m}$ path at $10^{-5}$ torr [43]. In this earlier study, the identity of this species has been confirmed as the protonated dimethyl ether ion, hypothesized to be a product of the protonated methanol dimer.

Within the ion source, the collision energy of the ions due to acceleration is expected to be minor because of the insignificant mean-free path, $\lambda$. However, at pressures of 1.0 to 0.1 torr in the region past the entrance cone, the value for $\lambda$ for $\left[\mathrm{CH}_{3} \mathrm{OH}\right]_{2}{ }^{+}$in $\mathrm{N}_{2}$ is $10^{-3}$ to
$10^{-2} \mathrm{~cm}$. Assuming a total distance of $3 \mathrm{~cm}$ in a potential field of $40 \mathrm{~V}$, the maximum attained kinetic energy of a dimer is 0.01 to $0.1 \mathrm{kcal} / \mathrm{mol}$. Although this is not a significant amount of energy, it may be enough to influence the branching ratio of either a dimer/ monomer precursor, or the fragmentation of the dimer itself.

\section{Generation of Solvent Ions from Acetonitrile with APPI}

With methanol, the photochemical characteristics are significantly affected by the presence of the dimer species. Unfortunately, experimental and theoretical thermodynamic data for acetonitrile vapor are limited, so we are restricted to a more qualitative analysis of ion chemistry that occurs within the source. The formation of an acetonitrile dimer has been studied using density functional theory, with an estimated dimerization $\Delta \mathrm{H}=$ $-4.02 \mathrm{kcal} / \mathrm{mol}$, formed as a weak hydrogen-bond between $\mathrm{C}-\mathrm{H} \cdots \mathrm{N}$ [44]. This is comparable to the methanol dimer bond energy, which is reported within a range of $3.45 \mathrm{eV}$ [45] to $6.04 \mathrm{eV}$ [37], suggesting that the density of acetonitrile dimer may be comparable to that for methanol dimer. Significant dimer:monomer ratios have been measured in supersonic expansions [46]; however, this is not representative of the high-temperature environment of an APPI source.

As is with the step-wise addition of neutral methanol to protonated methanol, acetonitrile undergoes a similar cluster growth process. Plašil and coworkers have used experimental evidence to suggest that upon generation of $\left[\mathrm{CH}_{3} \mathrm{CN}\right] \mathrm{H}^{+}$, the step-wise addition reaction occurs as a three-body collision with a reaction rate approaching the collision rate [47], generating the dimer $\left[\mathrm{CH}_{3} \mathrm{CN}\right]_{2} \mathrm{H}^{+}$. The experimental apparatus used by Plašil and coworkers operated at a reduced pressure of 3 to 5 torr. To determine the dominant solvent-ion species formed within the APPI source, the mass range from $m / z 0$ to 200 is measured for pure acetonitrile as a function of cone voltage (Figure 3).
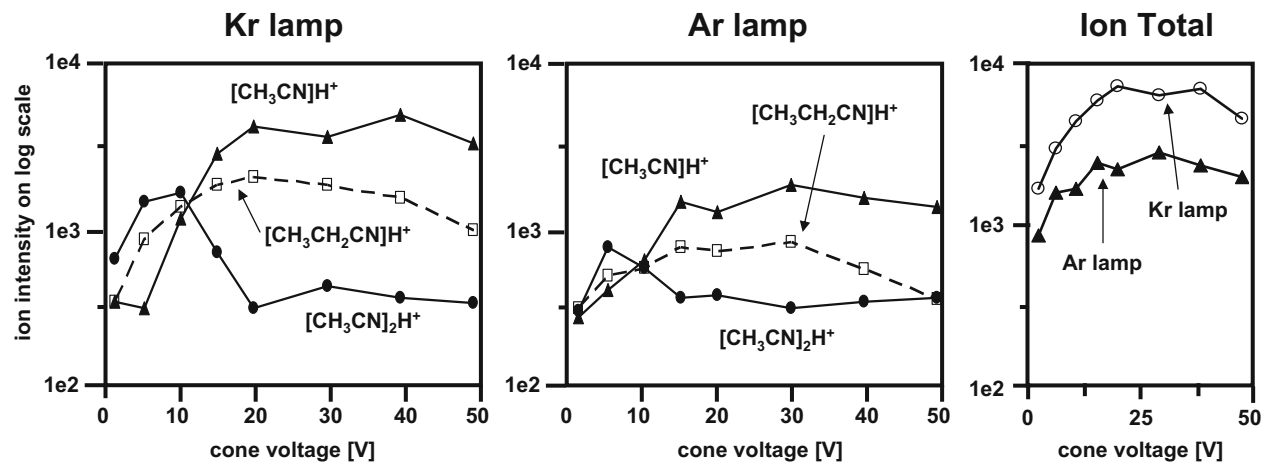

Figure 3. Ion intensity on a log scale for solvent species measured in acetonitrile (100 $\mu \mathrm{L} / \mathrm{min})$ using either a Kr lamp (left) or an Ar lamp (middle). Ion totals (right) represent the sum of all detected ion species using either of the two lamps. Both lamps produce similar ion species and concentrations. 
Three species were found using both $\mathrm{Kr}$ and $\mathrm{Ar}$ lamps. The protonated monomer and dimer of acetonitrile, $\left[\mathrm{CH}_{3} \mathrm{CN}\right] \mathrm{H}^{+}$and $\left[\mathrm{CH}_{3} \mathrm{CN}\right]_{2} \mathrm{H}^{+}$, and the ion $\left[\mathrm{CH}_{3} \mathrm{CH}_{2} \mathrm{CN}\right] \mathrm{H}^{+}$(propionitrile) were found in similar concentrations and ratios using either the $\mathrm{Kr}$ or $\mathrm{Ar}$ lamp. The total yield of the acetonitrile ions is about an order of magnitude less than what is observed for methanol (Figure 2 versus Figure 3), explained by the higher ionization potential for acetonitrile (IP $=12.2$ $\mathrm{eV})$, well above the energy of both $\mathrm{Kr}$ and Ar lamps. Thermospray ionization is not the source of ions, as when the lamp is turned off, ion signals are no longer detected. If we assume that the $\mathrm{CH}_{3} \mathrm{CN}^{+}-\mathrm{CH}_{3} \mathrm{CN}$ binding energy is comparable to the $33 \mathrm{kcal} / \mathrm{mol}$ ionmolecule binding energy for methanol, then we estimate a dimer ionization potential of about $10.9 \mathrm{eV}$ $(=12.2-(33 / 23.06)+(4.02 / 23.06) \mathrm{eV})$. This may explain why the acetonitrile ion yield is comparable for the Ar versus $\mathrm{Kr}$ lamp despite the much lower photon intensity of the Ar lamp. It is difficult to explain the mechanism of acetonitrile ionization using the Kr lamp, except perhaps due to a trimer or thermally excited dimer, which might be ionized by the $10.6 \mathrm{eV}$ emission from the $\mathrm{Kr}$ lamp. Another explanation proposed by Marotta and coworkers is a photoisomerization of $\mathrm{CH}_{3} \mathrm{CN}$ to a species $\mathrm{CH}_{2} \mathrm{CNH}$ that has a reduced ionization potential and can subsequently photoionize [48]. However this process requires a two-photon interaction, which is very unlikely for continuous, incoherent lights sources such as the $\mathrm{Kr}$ and Ar lamps used here.

The propionitrile ion signal is relatively strong indicating that it is not due to an impurity as previously theorized [49], but is possibly a product of some ionmolecule reaction. Furthermore, based on the appearance ionization potential (appearance potential refers to a fragment ion, e.g., in an electron ionization spectrum) of $11.70 \mathrm{eV}$ for propionitrile [50], had there been a propionitrile impurity, then the Ar lamp would have produced a noticeable increase in propionitrile ions. We believe that the propionitrile ion is formed by an ion-molecule reaction similar to that of reaction [5] for methanol. The experimental observations can be explained by a two-channel reaction that favors dimerization at low cone voltages, but at higher energies the formation of propionitrile,

$$
\begin{aligned}
\mathrm{CH}_{2} \mathrm{CNH}_{2}^{+}+\mathrm{CH}_{3} \mathrm{CN} \stackrel{\text { low cone voltage }}{=} & \left(\mathrm{CH}_{3} \mathrm{CN}\right)_{2} \mathrm{H}^{+}, \\
\mathrm{CH}_{2} \mathrm{CNH}_{2}^{+}+\mathrm{CH}_{3} \mathrm{CN} \stackrel{\text { high cone voltage }}{=} & \mathrm{CH}_{3} \mathrm{CH}_{2} \mathrm{CNH}^{+} \\
+ & \mathrm{HCN} .
\end{aligned}
$$

The reactions of eqs $6 \mathrm{a}$ and $6 \mathrm{~b}$ describe the observed drop in $\left[\mathrm{CH}_{3} \mathrm{CN}\right]_{2} \mathrm{H}^{+}$and concurrent rise in $\left[\mathrm{CH}_{3} \mathrm{CH}_{2} \mathrm{CN}_{2} \mathrm{H}^{+}\right.$seen in Figure 3. The generation of $\mathrm{HCN}$ would be favored due to the stabilization energy, although it appears to have a higher energy barrier that is only overcome at higher cone voltages.

\section{PAH Detection as a Function of Lamp Energy and Solvent Flow Rate}

Addition of a second-phase solvent in the mobile phase complicates the thermochemistry of the ion source considerably. For this reason, most of the data generated has focused on pure solvent systems, permitting a less complicated picture of ion chemistry within the source. However, as RP-HPLC-MS invariably uses more than one solvent, it is necessary to include some discussion here about such mixed solvent systems. Empirical studies have used mass spectrometry to determine what ions result in such mixtures. As an example, Stace and Shukla found that water impurities added to methanol result in mixed $\mathrm{CH}_{3} \mathrm{OH}: \mathrm{H}_{2} \mathrm{O}$ clusters [51]. The quantity of these clusters is greatest when the ratio of the two solvents approaches 1:1, as is with the solvent mixture studied here. The formation of larger clusters is thermodynamically favored, specifically, the stepwise addition of $\mathrm{CH}_{3} \mathrm{OH}$ to $\left[\mathrm{CH}_{3} \mathrm{OH}_{2} \cdot \mathrm{H}_{2} \mathrm{O}\right]^{+}$has a $\Delta \mathrm{H}=-24.6 \mathrm{kcal} / \mathrm{mol}$ [52]. The $\mathrm{CH}_{3} \mathrm{CN}: \mathrm{H}_{2} \mathrm{O}$ mixture also results in thermodynamically favored cluster formation [53], with a stepwise addition of $\mathrm{CH}_{3} \mathrm{CN}$ to $\left[\mathrm{CH}_{3} \mathrm{CNH} \cdot \mathrm{H}_{2} \mathrm{O}\right]^{+}$having a $\Delta \mathrm{H}=-23.4 \mathrm{kcal} / \mathrm{mol}$ [54].

As is seen in Table 2, when PAH compounds are measured using pure acetonitrile versus a $(1: 1) \mathrm{CH}_{3} \mathrm{CN}$ : $\mathrm{H}_{2} \mathrm{O}$ mixture, the signal decreases. This could be a result of a shift in the absorption spectrum, as predicted from the theoretical work by Ahn and Lee [53]. However, this decrease is observed equally for all three lamps; so we believe this to be independent of wave-

\begin{tabular}{|c|c|c|c|c|c|c|c|c|c|c|c|c|}
\hline \multirow[b]{2}{*}{ Compound } & \multicolumn{3}{|c|}{$\mathrm{CH}_{3} \mathrm{OH}$} & \multicolumn{3}{|c|}{$\mathrm{CH}_{3} \mathrm{OH}: \mathrm{H}_{2} \mathrm{O}(1: 1)$} & \multicolumn{3}{|c|}{$\mathrm{CH}_{3} \mathrm{CN}$} & \multicolumn{3}{|c|}{$\mathrm{CH}_{3} \mathrm{CN}: \mathrm{H}_{2} \mathrm{O}(1: 1)$} \\
\hline & $\mathrm{Xe}$ & $\mathrm{Kr}$ & $\mathrm{Ar}$ & $\mathrm{Xe}$ & $\mathrm{Kr}$ & $\mathrm{Ar}$ & $\mathrm{Xe}$ & $\mathrm{Kr}$ & $\mathrm{Ar}$ & $\mathrm{Xe}$ & $\mathrm{Kr}$ & Ar \\
\hline Benzo[a]pyrene & 3.8 & 21 & 38 & 1.3 & 7.2 & 6.6 & 3.9 & 4.7 & 1.7 & 2.4 & 2.9 & 1.6 \\
\hline 1,2-Benz-anthracene & 1.6 & 10 & 2.1 & 0.2 & 0.2 & 0.1 & 1.4 & 1.3 & 0.3 & 2.1 & 2.0 & 1.0 \\
\hline Indeno[1,2,3-c,d]pyrene & 2.5 & 12 & 4.5 & 0.9 & 1.8 & 1.4 & 3.8 & 4.0 & 2.4 & 1.6 & 1.9 & 0.5 \\
\hline
\end{tabular}
length for the VUV region studied here. Likely, there is

Table 2. Absolute signal intensity of $\mathrm{PAH}$ mixture ${ }^{\mathrm{a}}$ with various lamps and mobile phases

All values use a cone voltage of $86 \mathrm{~V}$ to increase the $\left[\mathrm{M}^{-}\right]^{+}:[\mathrm{M}+1]^{+}$ion ratio and maximize overall ion intensity (units are $\times 10^{3}$ a.u.). Maxima signals per compound per lamp are bolded.

aEach PAH is $1 \mathrm{ng}$ total per injection at a flow of $100 \mu \mathrm{L} / \mathrm{min}$. 

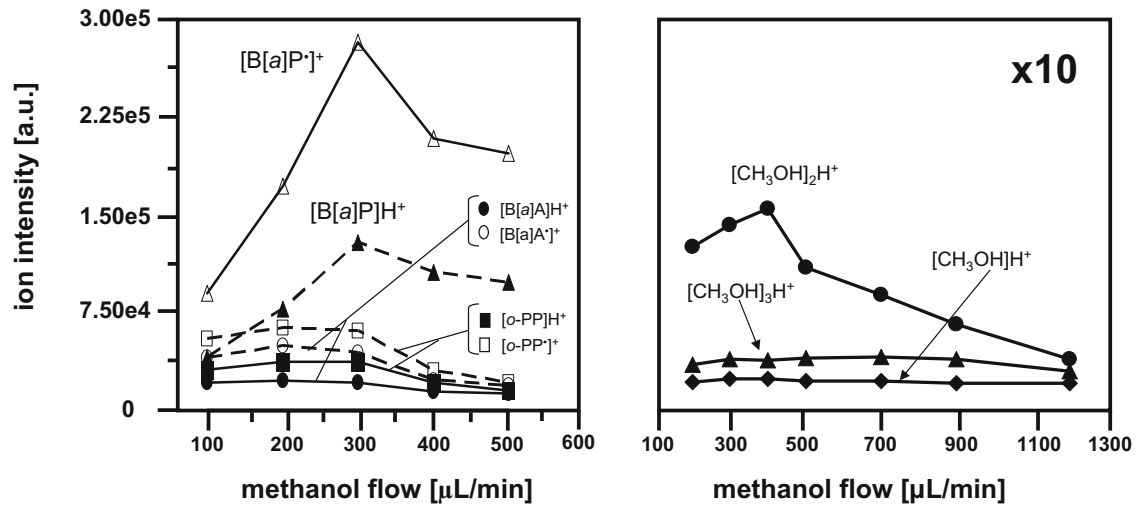

Figure 4. (left) Measurement of PAH compounds at ideal cone voltages at increasing flow. (right) Measured ion intensity $(\times 10)$ at a low cone voltage of $5 \mathrm{~V}$ (minimal fragmentation) with increasing methanol flow. Both measurements use a $\mathrm{Kr}$ lamp. $\left[\mathrm{M}^{-}\right]^{+}$and $[\mathrm{M}+\mathrm{H}]^{+}$have been corrected for isotopic abundances.

rather a decrease in the PA of mixed $\mathrm{CH}_{3} \mathrm{CN}: \mathrm{H}_{2} \mathrm{O}$ clusters relative to pure $\mathrm{CH}_{3} \mathrm{CN}$ clusters, making the former protonated cluster ion more likely to transfer its proton to the analyte.

Given that the proton affinities (PA) of $\left[\mathrm{CH}_{3} \mathrm{CN}\right]$ and $\left[\mathrm{CH}_{3} \mathrm{CN}\right]_{2}$ are greater than that of the analyte (see below), proton transfer from the solvent ions to the analyte (PAH) is not thermodynamically favored. Also, all ion species are generated at low concentrations and in approximately equal ratios using either of the two lamps. Thus, the energy of light is not critical in solvent-ion generation. However, given that (1) the absorption cross-section is higher for the Ar lamp, and (2) the Kr lamp produces significantly more light than the Ar lamp, then production of target analyte ion (see Table 2) likely results mostly from direct photoionization, followed by $\mathrm{H}$-abstraction from acetonitrile by
$[\mathrm{M}]^{+}$. Using the solvent methanol provides the highest signal intensity for all three PAH compounds, a consequence of enhanced analyte signal via photoionizationinduced chemical ionization (see discussion below).

\section{PAH Detection as a Function of Methanol} Flow Rate

To determine why the higher flow provides a better sensitivity for trace analytes with methanol and an $\mathrm{Ar}$ lamp, the solvent ions are measured versus flow (see Figure 4). A reduced cone voltage is used to minimize collision fragmentation to more accurately reflect the ions that exist in the ionization region at atmospheric pressure. When the flow is increased, the concentration of the protonated methanol dimer is a maximum in the region of 300 to $400 \mu \mathrm{L} / \mathrm{min}$ (Figure 4 , left), which

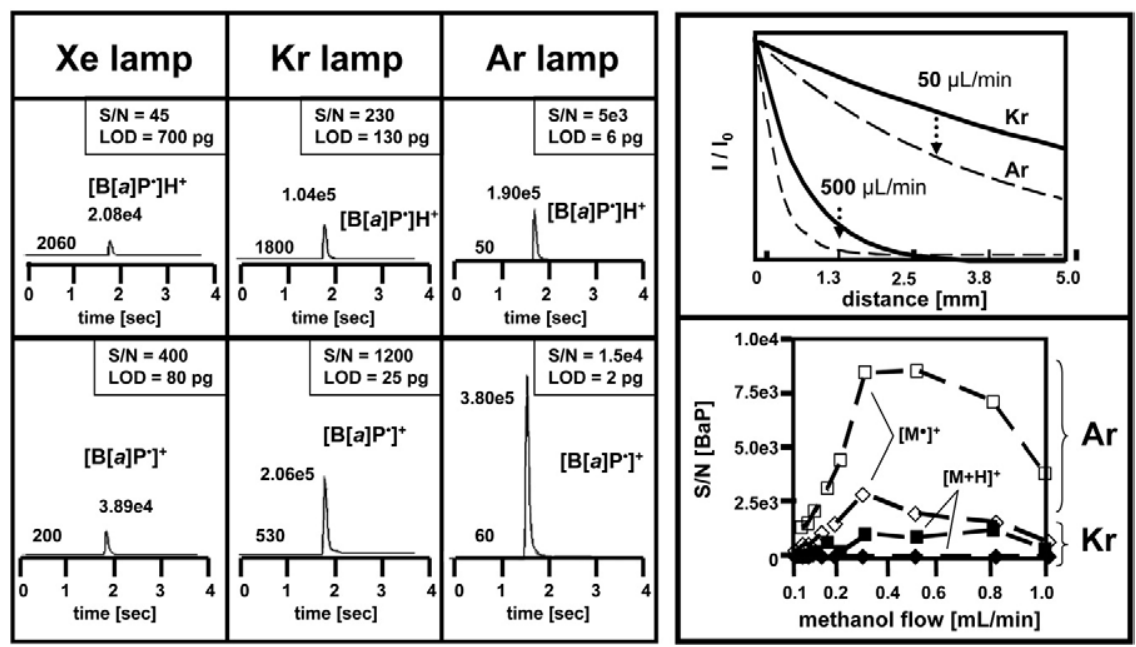

Figure 5. (left) Plots of SIM for $\left[\mathrm{M}^{*}\right]^{+}(86 \mathrm{~V})$ and $[\mathrm{M}+\mathrm{H}]^{+}(34 \mathrm{~V})$ of benzo[a]pyrene using a Xe, $\mathrm{Kr}$, or Ar lamp for photoionization with $100 \mu \mathrm{L} / \mathrm{min}$ methanol. Dramatic reduction in background of SIM signal is measured with the Ar lamp compared to the Xe or Kr lamps. (right, top) Relative light transmission for $\mathrm{Kr}$ and Ar lamps at low and high flow, (right, bottom) and the resulting $\mathrm{S} / \mathrm{N}$ ratio for increased flow with $\mathrm{Kr}$ and Ar lamps. $\left[\mathrm{M}^{-}\right]^{+}$and $[\mathrm{M}+\mathrm{H}]^{+}$have been corrected for isotopic abundances. 
Table 3. The $\mathrm{S} / \mathrm{N}$ of a PAH mixture ${ }^{\mathrm{a}}$ in acetonitrile at 100 or $500 \mu \mathrm{L} / \mathrm{min}$ with $\mathrm{Kr}$ or Ar lamps

\begin{tabular}{|c|c|c|c|c|c|c|}
\hline \multirow[b]{2}{*}{ Acetonitrile flow } & \multicolumn{2}{|c|}{ Benzo[a]pyrene } & \multicolumn{2}{|c|}{ Benz[a]anthracene } & \multicolumn{2}{|c|}{$\begin{array}{l}\text { Indeno[1,2,3- } \\
\text { c,d]pyrene }\end{array}$} \\
\hline & $\mathrm{Kr}$ & $\mathrm{Ar}$ & $\mathrm{Kr}$ & $\mathrm{Ar}$ & $\mathrm{Kr}$ & $\mathrm{Ar}$ \\
\hline $100 \mu \mathrm{L} / \mathrm{min}$ & 361 & 233 & 328 & 76 & 349 & 144 \\
\hline $500 \mu \mathrm{L} / \mathrm{min}$ & 193 & 294 & 32 & 105 & 111 & 175 \\
\hline
\end{tabular}

Dominant species detected and reported here are $\left[\mathrm{M}^{\cdot}\right]^{+}$.

${ }^{\mathrm{a}}$ Each $\mathrm{PAH}$ is $1 \mathrm{ng}$ total per injection.

correlates to the observed maximum sensitivity for the PAH ion intensities (Figure 4, right). This provides further evidence that at higher flow rates, chemical ionization of the neutral analyte species, $[\mathrm{M}]$, with $\left[\mathrm{CH}_{3} \mathrm{OH}\right]_{2} \mathrm{H}^{+}$results in $[\mathrm{M}+\mathrm{H}]^{+}$and is, therefore, the dominant mechanism for PAH detection in this case.

In Figure 5, ion signals are monitored at increasing methanol flow using a $\mathrm{Xe}, \mathrm{Kr}$, or Ar lamp. The typical operating conditions for an APPI system are for low flows, i.e., $<100 \mu \mathrm{L} / \mathrm{min}$, which assumes that the solvent only behaves as an absorbing medium and does not contribute to the ionization process. Although the light transmission through methanol vapor is highest with the Xe lamp, the measured signal intensity using the Xe lamp is lowest. The highest signal is measured with the Ar lamp, which has the lowest light transmission. With methanol, the majority solvent species $\left[\mathrm{CH}_{3} \mathrm{OH}\right]$ is ionized, resulting in chemical ionization. Since the sensitivity of a chemical ionization reaction is proportional to the amount of reagent, a higher flow is favored. This is especially evident with the Ar lamp, where the LOD for benzo[a]pyrene is $2 \mathrm{pg}$ at 100 $\mu \mathrm{L} / \mathrm{min}$, but $500 \mathrm{fg}$ at 400 to $500 \mu \mathrm{L} / \mathrm{min}$. This is similar to the signal enhancement obtained with a dopant; however, in this case, the solvent itself acts as a dopant.

A significant feature of the SIM signals in Figure 5 is the dramatic reduction of background noise when the Ar lamp is used. One explanation to this is the same effect observed in Figure 3, i.e., the dramatic reduction in adduct formation when the Ar lamp is used versus the Kr lamp. The generation of thermal electrons from the photoionization of methanol could also explain why the background ion signal is greatly reduced; however we would expect a concurrent decrease in sample signal.

\section{PAH Detection as a Function of Acetonitrile Flow Rate}

To explore the effects of using higher-energy light with the detection of both $[\mathrm{M}]^{+}$and $[\mathrm{M}+\mathrm{H}]^{+}$ions in a PAH mixture using acetonitrile, the $\mathrm{S} / \mathrm{N}$ ratios were determined using both the $\mathrm{Kr}$ and Ar lamps at low and high flow rates of acetonitrile (Table 3). For both lamps the parent ion, $[\mathrm{M}]^{+}$, is the dominant ion produced. The signal intensity for $[\mathrm{M}+\mathrm{H}]^{+}$and $[\mathrm{M}]^{+}$drops with increasing flow rate for both the $\mathrm{Kr}$ and Ar lamps. However, unlike with methanol, [1] the Kr lamp results in an increase in $[\mathrm{M}]^{+}$signal compared with the Ar lamp and [2] the $[\mathrm{M}]^{+}$is the dominant ion species detected. For all three test compounds, the $\mathrm{Kr}$ lamp results in a better $\mathrm{S} / \mathrm{N}$ ratio at a low flow rate, while the Ar lamp results in a better $\mathrm{S} / \mathrm{N}$ ratio at a high flow rate.

A relatively higher concentration of $[\mathrm{M}]^{+}$is expected if direct photoionization - and not chemical ionization-is the dominant means of ion generation within the source. However, there is a notable contribution of $[\mathrm{M}+\mathrm{H}]^{+}$ ions, which can be explained by either direct photoionization of $[\mathrm{M}]$ followed by hydrogen abstraction, or possibly a result of a chemical ionization scheme, proposed by Marotta et al. [48], which is (1) photo-induced isomerization of acetonitrile, (2) autoionization, resulting in a nonacidic, radical species, (3) proton abstraction from neutral acetonitrile, resulting in an acidic species, and (4) proton abstraction by $[\mathrm{M}]$, resulting in $[\mathrm{M}+$ $\mathrm{H}]^{+}$. However, given that the hydrogen abstraction reaction is a single bimolecular reaction, whereas the chemical ionization scheme requires two bimolecular collisions to occur, we believe that it is hydrogen abstraction reaction that is the dominant mechanism resulting in $[\mathrm{M}+\mathrm{H}]^{+}$ions.

\section{Effects of Cone Voltage on Detected PAH Ions}

Recent work done with APLI has shown that when the ionization occurs far from the sample cone, the dominant ion observed is $[\mathrm{M}+\mathrm{H}]^{+}$, but when the laser is directed at the entrance of the cone, the dominant signal observed is [M] $]^{+}$[55]. A similar effect has also been observed to occur in a low-pressure PPI source, where $[\mathrm{M}]^{+}$ions occur close to the sampling cone and $[\mathrm{M}+$ $\mathrm{H}]^{+}$ions occur with greater abundance farther away from the cone [16]. With APLI, direct photoionization of $[\mathrm{M}]$ to $[\mathrm{M}]^{+}$occurs within the ionization volume, and as the position of the laser beam is backed away from the sampling cone, then either the "slow" H-abstraction [16], or "fast" $\mathrm{H}^{+}$-transfer reactions can result in generation of $[\mathrm{M}+\mathrm{H}]^{+}$[17]. With APPI, the source of photons is relatively distant from the sampling cone, and thus chemical ionization can make significant contribution to ion generation.

The analyte ion generated within an APPI ion source is not directly measured, but first passes through a sampling cone (variable voltage) into the first reduced pressure stage, and subsequently passes through an extraction electrode (fixed voltage) to the mass ana- 

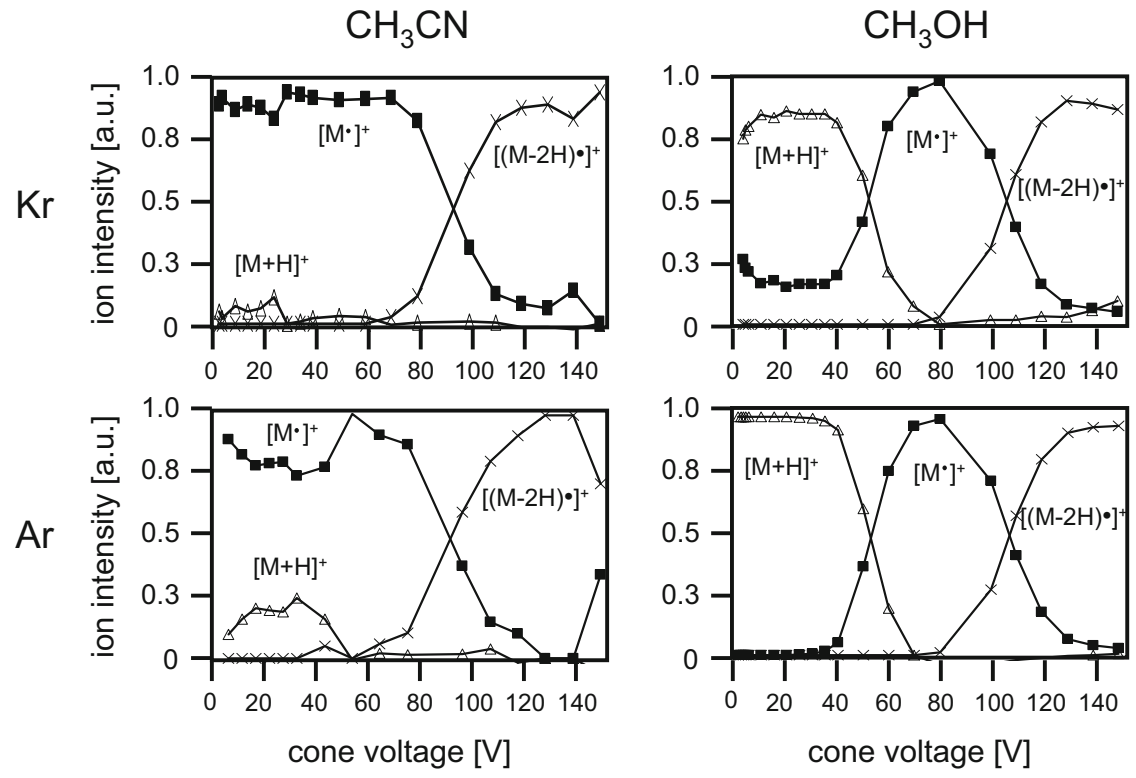

Figure 6. Plot of fractional signals for $[\mathrm{M}+\mathrm{H}]^{+},\left[\mathrm{M}^{*}\right]^{+}$and $\left[(\mathrm{M}-2 \mathrm{H})^{*}\right]^{+}$for benzo $[a]$ pyrene versus cone voltage in $100 \mu \mathrm{L} / \mathrm{min}$ flow of acetonitrile (left column) or methanol (right column) using a Kr lamp (top row) or an Ar lamp (bottom row). $\left[\mathrm{M}^{*}\right]^{+}$and $[\mathrm{M}+\mathrm{H}]^{+}$have been corrected for isotopic abundances.

lyzer. The voltage difference between the sampling cone and the extraction electrode creates an ion path that follows a "Z"-configuration and, thus, has an ion-transmission efficiency that is dependent upon this voltage difference. Unfortunately, although a higher voltage on the sampling cone improves ion-transmission efficiency, the resulting ion acceleration and, thus, collision-induced reactions can react away the original ion species.

The intensity of an ion signal as a function of cone voltage can be made approximately independent of the ion-transmission efficiency by normalizing each ion to the total of the ion signals to examine the effects of collision-induced reactions. In this way, one can generate a plot that indicates the ratio of initial ions present within the ion source (at low cone voltages) and the resulting reaction pathways that occur as the collisioninduced reactions become significant (at high cone voltages). For this experiment, a total mass injection of $5 \mathrm{ng}$ benzo[a]pyrene was measured using a mobile phase of either acetonitrile or methanol and either a $\mathrm{Kr}$ or Ar lamp (Figure 6). The analyte samples were prepared using the same solvent as the mobile phase.

Analysis of benzo[a]pyrene with acetonitrile as a mobile phase results in both the production of $[\mathrm{M}]^{+}$ and $[\mathrm{M}+\mathrm{H}]^{+}$within the ion source, with roughly similar ratios for both the $\mathrm{Kr}$ and Ar lamp. If $\mathrm{CI}$ is the dominant mechanism for production of $[\mathrm{M}+\mathrm{H}]^{+}$ within the ion source, then the proton donor is likely $\left[\mathrm{CH}_{3} \mathrm{CN}\right]_{2} \mathrm{H}^{+}$(see Figure 3). As the $\mathrm{Kr}$ lamp results in a greater production of protonated acetonitrile compared with the Ar lamp by two orders of magnitude, one would expect that the $[\mathrm{M}+\mathrm{H}]^{+}$versus $[\mathrm{M}]^{+}$signal would be substantially improved using the $\mathrm{Kr}$ lamp. However, this is not what is seen. Although the abso- lute ion intensity is much greater when using the $\mathrm{Kr}$ lamp, both ions stay proportionally the same (Figure 6, left column). This enhanced signal is likely a result of the much greater photon count from a Kr lamp, as well as the lower photoabsorption of light from the $\mathrm{Kr}$ lamp versus the Ar lamp (see Table 1). The dominant mechanism occurring with acetonitrile to generate analyte ions within the source is therefore simple photo-ionization, resulting in $[\mathrm{M}]^{+}$, not chemical ionization.

The relatively small $[\mathrm{M}+\mathrm{H}]^{+}$signal with $\mathrm{CH}_{3} \mathrm{CN}$ with both $\mathrm{Kr}$ and Ar lamps is probably because the proton affinity (PA) for $\left[\mathrm{CH}_{3} \mathrm{CN}_{2} \mathrm{H}^{+}\right.$is greater than the PA of benzo[a]pyrene, $-212 \mathrm{kcal} / \mathrm{mol}$ [56]. To test this hypothesis, one may consider the PA for $\mathrm{CH}_{3} \mathrm{CN}$, $-189.2 \mathrm{kcal} / \mathrm{mol}$, [57] compared with $-181.9 \mathrm{kcal} / \mathrm{mol}$ for $\mathrm{CH}_{3} \mathrm{OH}$. Since the PA for $\mathrm{CH}_{3} \mathrm{CN}$ is greater than for $\mathrm{CH}_{3} \mathrm{OH}$, it is reasonable to assume that the stepwise solvation energies for addition of a neutral $\mathrm{CH}_{3} \mathrm{CN}$ to $\left[\mathrm{CH}_{3} \mathrm{CN}\right] \mathrm{H}^{+}$are at least as large as that for the equivalent cluster ion binding for $\mathrm{CH}_{3} \mathrm{OH}$ that were reported earlier. Given a solvation energy of $-31 \mathrm{kcal} / \mathrm{mol}$ for $\mathrm{CH}_{3} \mathrm{CN}+\left[\mathrm{CH}_{3} \mathrm{CN}\right] \mathrm{H}^{+} \rightarrow\left[\mathrm{CH}_{3} \mathrm{CN}\right]_{2} \mathrm{H}^{+}[58]$, we arrive at an estimated PA value for $\left[\mathrm{CH}_{3} \mathrm{CN}\right]_{2}$ of $-220 \mathrm{kcal} / \mathrm{mol}$. This is $-8 \mathrm{kcal} / \mathrm{mol}$ greater than for benzo[a]pyrene, and thus the chemical ionization route to producing $[\mathrm{M}+$ $\mathrm{H}^{+}$is not expected to occur in the source with a mobile phase of $\mathrm{CH}_{3} \mathrm{CN}$.

The intensity of benzo[a]pyrene ions with methanol as a mobile phase is several orders of magnitude higher than with acetonitrile. From Figure 2, the dominant solvent ion within the source is determined to be $\left[\mathrm{CH}_{3} \mathrm{OH}\right]_{2} \mathrm{H}^{+}$for both the Ar and $\mathrm{Kr}$ lamps although, as discussed above, the Ar lamp is more efficient at generating this ion. The PA for $\mathrm{CH}_{3} \mathrm{OH}$ is -181.9 $\mathrm{kcal} / \mathrm{mol}$, and given that the stepwise addition of a 
neutral $\mathrm{CH}_{3} \mathrm{OH}$ to $\left[\mathrm{CH}_{3} \mathrm{OH}\right] \mathrm{H}^{+}$is $-33 \mathrm{kcal} / \mathrm{mol}$, the PA for the dimer can be estimated to be $-214.9 \mathrm{kcal} /$ mol. This is only slightly $(-3 \mathrm{kcal} / \mathrm{mol})$ greater than for benzo[ $a]$ pyrene and, thus, the chemical ionization route to producing $[\mathrm{M}+\mathrm{H}]^{+}$is expected to occur within the ion source, especially considering the large excess of protonated dimer versus neutral benzo[a]pyrene within the source (equilibrium advantage).

As the PA of the methanol dimer is much less than the target analyte, chemical ionization is the dominant means of ion generation within the ion source (Figure 6, right column). Some photoionization of the target analyte does occur with the Kr lamp and not the Ar lamp, resulting in $\left[\mathrm{M}^{-}\right]^{+}$, because the photoabsorption of light generated from the $\mathrm{Kr}$ lamp is much less than the Ar lamp (see Table 1). This leads to a minor contribution of about $20 \%[\mathrm{M}]^{+}$within the ion source. Thus, the dominant mechanism occurring with benzo[a]pyrene using methanol as a mobile phase is PI-induced solvent chemical ionization and not direct photoionization.

In both cases, as the sampling cone voltage is increased, the $[\mathrm{M}+\mathrm{H}]^{+}$adduct decreases and is replaced by $[\mathrm{M}]^{+}$, which is later replaced by $[(\mathrm{M}-2 \mathrm{H})]^{+}$at even higher cone voltages. This is similar to the observations of methanol and acetonitrile clusters. As mentioned above, the resulting kinetic energy is small (few $\mathrm{kcal} / \mathrm{mol}$ at most). However, in all studied cases, there is a clear correlation between signal loss of adducts or clusters and a rise in cone voltage (resulting in an increase in translational KE of the ions). Possible explanations include branching fragmentation channels with only slight energy differences, or surface-induced chemistry at the cone's surface [59]. We believe it is the first of these possibilities, as the surfaces had been recently cleaned with formic acid, and also we would not expect that a laminar flow of ions through the sample cone would interact with the surface.

\section{Conclusions}

In this study, we present a comparison analysis using APPI-LC-MS with three PAHs and three different VUV lamps, $\mathrm{Xe}, \mathrm{Kr}$, and Ar. Currently, the $\mathrm{Kr}$ lamp is the most commonly used source of photoionizing light for APPI. The purpose of this study is to demonstrate that different photon energies provide unique advantages for each lamp under different conditions. Three main conclusions derive from this work:

- For methanol, the $\mathrm{Kr}$ lamp can ionize methanol dimer, whereas the Ar lamp can ionize dimer and monomer. The ionized methanol reacts with the abundance of neutral solvent to form a variety of protonated monomer and cluster solvent ions, which are efficient proton-donating agents for ionizing analyte molecules.

- Though the light output from an Ar lamp is much less than from a Kr lamp, the greatly enhanced production of methanol dimer ions from the Ar lamp can result in greater analyte ion signal intensity. Also, for the analytes studied here, the Ar lamp provided a greatly reduced noise with SIM, improving the S/N ratio.

- For acetonitrile mobile phase, the yield of acetonitrile ions is much less than for methanol mobile phase due to the higher ionization potential of acetonitrile. This results in less ionization by ion-analyte reactions than for methanol.

- Since acetonitrile has a higher proton affinity than methanol, the protonated solvent monomer and cluster ions are not efficient protonating agents, further reducing the ionization of analyte relative to methanol.

\section{Acknowledgments}

The authors are grateful for insightful conversations with Dr. Thorsten Benter (Bergische University, Wuppertal) on PI and APPI mechanisms, and with Dr. Karl Hanold on APPI mechanisms and details of instrument effects. This work is partially supported by the National Institute of Health (SBIR Phase II, GM063430).

\section{References}

1. Syage, JA; Evans, MD; Hanold, KA. Photoionization Mass Spectrometry. Am. Lab. 2000, 32, 24-29.

2. Robb, D.; Covey, T.; Bruins, A. Atmospheric Pressure Photoionization: An Ionization Method for Liquid Chromatography-Mass Spectrometry. Anal. Chem. 2000, 72, 3653-3659.

3. Constapel, M.; Schellenträger, M.; Schmitz, O.; Gäb, S.; Brockmann, K.; Giese, R.; Benter, T. Atmospheric Pressure Laser Ionization: A Novel Ionization Method for Liquid Chromatography/Mass Spectrometry. Rapid Commun. Mass Spectrom. 2005, 19, 326-336.

4. Cai, S. S.; Syage, J. A. Atmospheric Pressure Photoionization Mass Spectrometry for Analysis of Fatty Acids and Acylglycerol Lipids. J. Chromatogr. A 2006, 1110, 15-26.

5. Cai, S. S.; Syage, J. A. Comparison of Atmospheric Pressure Photoionization, Atmospheric Pressure Chemical Ionization, and Electrospray Ionization Mass Spectrometry for Analysis of Lipids. Anal. Chem. 2006, 78, 1191-1199.

6. Trösken, E. R.; Straube, E.; Lutz, W. K.; Völkel, W.; Patten, C. Quantitation of Lanosterol and Its Major Metabolite FF-MAS in an Inhibition Assay of CYP51 by Azoles with Atmospheric Pressure Photoionization Based LC-MS/MS. J. Am. Soc. Mass Spectrom. 2004, 15(8), 1216-1221.

7. Hanold, K. A.; Fischer, S. M.; Cormia, P.; Miller, C. E.; Syage, J. A. Atmospheric Pressure Photoionization (APPI): I. General Properties for LC/MS. Anal. Chem. 2004, 76, 2842-2851.

8. Delobel, A.; Halgand, F.; Laffranchise-Gosse, B.; Snijders, H.; Laprevote, O. Characterization of Hydrophobic Peptides by Atmospheric Pressure Photoionization-Mass Spectrometry and Tandem Mass Spectrometry. Anal. Chem. 2003, 75(21), 5961-5968.

9. Takino, M.; Daishima, S.; Nakahara, T. Determination of Chloramphenicol Residues in Fish Meats by Liquid Chromatography-Atmospheric Pressure Photoionization Mass Spectrometry. J. Chromatogr. A 2003, 1011(1/2), 67-75.

10. Yoshioka, N.; Akiyama, Y.; Teranishi, K. Rapid Simultaneous Determination of o-Phenylphenol, Diphenyl, Thiabendazole, Imazalil, and Its Major Metabolite in Citrus Fruits by Liquid Chromatography-Mass Spectrometry Using Atmospheric Pressure Photoionization. J. Chromatogr. A 2004, 1022(1/2), 145-150.

11. Hakala, K.; Laitinen, L.; Kaukonen, A.; Hirvonen, J.; Kostianen, R. Kotiaho, T. Development of LC/MS/MS Methods for Cocktail Dosed Caco-2 Samples Using Atmospheric Pressure Photoionization and Electrospray Ionization. Anal. Chem. 2003, 75, 5969-5977.

12. Greig, M.; Bolaños, B.; Quenzer, T.; Bylund, J. Fourier Transform Ion Cyclotron Resonance Mass Spectrometry Using Atmospheric Pressure Photoionization for High-Resolution Analyses of Corticosteroids. Rapid Commun. Mass Spectrom. 2003, 17(24), 2763-2768.

13. Lembcke, J.; Ceglarek, U.; Fiedler, G.; Baumann, S.; Leichtle, A.; Thiery, J. Rapid Quantification of Free and Esterified Phytosterols in Human Serum Using APPI-LC-MS/MS. J. Lipid Res. 2005, 46, 21-26.

14. van Leeuwen, S.; Hendriksen, L.; Karst, U. Determination of Aldehydes and Ketones Using Derivatization with 2,4-Dinitrophenylhydrazine (DNPH) and Liquid Chromatography/Atmospheric Pressure PhotoionizationMass Spectrometry (LC/APPI-MS). J. Chromatogr. A 2004, 1058, 107-112. 
15. Takino, M.; Daishima, S.; Nakahara, T. Determination of Perfluorooctane Sulfonate in River Water by Liquid Chromatography/ Atmospheric Pressure Photoionization Mass Spectrometry by Automated On-Line Extraction Using Turbulent Flow Chromatography. Rapid Commun. Mass Spectrom. 2003, 17(5), 1965-1972.

16. Syage, J. Mechanism of $[\mathrm{M}+\mathrm{H}]+$ Formation in Photoionization Mass Spectrometry. J. Am. Soc. Mass Spectrom. 2004, 15, 1521-1533.

17. Robb, D.; Blades, M. Effects of Solvent Flow, Dopant Flow, and Lamp Current on Dopant-Assisted Atmospheric Pressure Photoionization (DA-APPI) for LC-MS. Ionization Via Proton Transfer. J. Am. Soc. Mass Spectrom. 2005, 16, 1275-1290.

18. Kauppila, T.; Bruins, A. Effect of Solvent Flow Rate on the Ionization Efficiency in Atmospheric Pressure Photoionization-Mass Spectrometry. J. Am. Soc. Mass Spectrom. 2005, 16, 1399-1407.

19. Robb, D. B.; Blades, M. W. Factors Affecting Primary Ionization in Dopant-Assisted Atmospheric Pressure Photoionization (DA-APPI) for LC/MS. J. Am. Soc. Mass Spectrom. 2006, 17, 130-138.

20. Clar, E.; Schmidt, W. Correlations Between Photoelectron and Phosphorescence Spectra of Polycyclic Hydrocarbons. Tetrahedron 1976, 32, 2563.

21. Akiyama, I.; Harvey, R. G.; LeBreton, P. R. Ultraviolet Photoelectron Studies of Methyl-Substituted Benz[a]Anthracenes. J. Am. Chem. Soc. 1981, 103, 6330 .

22. Jochims, H. W.; Rasekh, H.; Ruhl, E.; Baumgartel, H.; Leach, S. The Photofragmentation of Naphthalene and Azulene Monocations in the Energy Range 2 to $22 \mathrm{eV}$. Chem. Phys. 1992, 168, 159.

23. Dewar, M. J. S.; Haselbach, E.; Worley, S. D. Calculated and Observed Ionization Potentials of Unsaturated Polycyclic Hydrocarbons; Calculated Heats of Formation by Several Semiempirical SCFMO Methods. Proc. Roy. Soc. (London) March 2003.

24. Kanda, K.; Nagata, T.; Ibuki, T. Photodissociation of Some Simple Nitriles in the Extreme Vacuum Ultraviolet Region. Chem. Phys. 1999, 243(1/2), 89-96.

25. Suto, M.; Lee, L. C. Photoabsorption Cross-Section of Ch3cnPhotodissociation Rates by Solar Flux and Interstellar Radiation. J. Geophys. Res. Atmos. 1985, 90(D7), 3037-3040.

26. Harich, S.; Lin, J. J.; Lee, Y. T.; Yang, X. Competing Atomic and Molecular Hydrogen Pathways in the Photodissociation of Methanol at 157 nm. J. Chem. Phys. 1999, 111(1), 5-9.

27. Nee, J. B.; Suto, M.; Lee, L. C. Photoexcitation Processes of Ch3ohRydberg States and Photofragment Fluorescence. Chem. Phys. 1985, 98(1), 147-155.

28. Fillion, J. H.; Ruiz, J.; Yang, X. F.; Castillejo, M.; Rostas, F.; Lemaire, J. L. High Resolution Photoabsorption and Photofragment Fluorescence Spectroscopy of Water Between 10.9 and 12 eV. J. Chem. Phys. 2004, 120(14), 6531-6541.

29. Mota, R.; Parafita, R.; Giuliani, A.; Hubin-Franskin, M. J.; Lourenco, J. M. C.; Garcia, G.; Hoffmann, S. V.; Mason, N. J.; Ribeiro, P. A.; Raposo, M.; Limao-Vieira, P. Water VUV Electronic State Spectroscopy by Synchrotron Radiation. Chem. Phys. Lett. 2005, 416(1/3), 152-159.

30. Koizumi, H.; Yoshimi, T.; Shinsaka, K.; Ukai, M.; Morita, M.; Hatano, Y.; Yagishita, A.; Ito, K. VUV-Optical Oscillator Strength Distributions of C3H6 and C4H8 Isomers. J. Chem. Phys. 1986, 82(11), 4856-4861.

31. Salahub, D. R.; Sandorfy, C. Far-Ultraviolet Spectra of Some Simple Alcohols and Fluoroalcohols. Chem. Phys. Lett. 1971, 8(1), 71-74.

32. Ogawa, M.; Cook, G. R. Absorption Coefficients of Methyl, Ethyl, Normal-Propyl, and Normal-Butyl Alcohols. J. Chem. Phys. 1958, 28(4), 747-748.

33. Au, J. W.; Cooper, G.; Burton, G. R.; Olney, T. N.; Brion, C. E. The Valence Shell Photoabsorption of the Linear Alkanes, Cnh2 $\mathrm{n}+2(\mathrm{~N}=$ -8)-Absolute Oscillator-Strengths (7-220 Ev). Chem. Phys. 1993, 173(2), 209-239.

34. Feng, R. F.; Brion, C. E. Absolute Photoabsorption Cross-Sections (Oscillator Strengths) for Ethanol (5-200 eV). Chem. Phys. 2002, 282(3), 419-427.

35. Russel, B. R.; Edwards, L. O.; Raymonda, J. W. Vacuum Ultraviolet Absorption Spectra of the Chloromethanes. J. Chem. Phys. 1973, 59, 6577-6586.

36. Seccombe, D. P.; Tuckett, R. P.; Baumgartel, H.; Jochims, H. W. Vacuum-UV Fluorescence Spectroscopy of CCl3F, $\mathrm{CCl} 3 \mathrm{H}$, and $\mathrm{CCl} 3 \mathrm{Br}$ in the Range 8-30 eV. Phys. Chem., Chem. Phys. 1999, 1(5), 773-782.

37. Provencal, R. A.; Paul, J. B.; Roth, L.; Chapo, C.; Casaes, R. N.; Saykally, R. J.; Tschumper, G. S.; Schaeffer, H. F. III. Infrared Cavity Ringdown
Spectroscopy of Methanol Clusters: Single Donor Hydrogen Bonding. J. Chem. Phys. 1999, 110(9), 4258-4267.

38. Tomoda, S.; Kimura, K. A Photoelectron Spectroscopic Estimation of the Concentrations of Simple Hydrogen-Bonded Dimers Produced in the Temperature-Controlled Supersonic Nozzle Beam. Bull. Chem. Soc. (Jpn.) 1983, 56(6), 1768-1771.

39. Curtiss, L. A.; Blander, M. Thermodynamic Properties of Gas-Phase Hydrogen-Bonded Complexes. Chem. Rev. 1988, 88, 827-841.

40. Kell, G. S.; McLaurin, G. E. Virial Coefficients of Methanol from 150 to $300^{\circ} \mathrm{C}$ and Polymerization in the Vapor. J. Chem. Phys. 1969, 51, 4345-4352.

41. Tsai, S. T.; Jiang, J. C.; Lee, Y. T.; Kung, A. H.; Lin, S. H.; Ni, C. K. Photoionization of Methanol Dimer Using a Tunable Vacuum Ultraviolet Laser. J. Chem. Phys. 1999, 111(8), 3434-3440.

42. Grimsrud, E. P.; Kebarle, P. Gas Phase Ion Equilibriums Studies of the Hydrogen Ion by Methanol, Dimethyl Ether, and Water. Effect of Hydrogen Bonding. J. Am. Chem. Soc. 1973, 95(24), 7939-7943.

43. Henis, J. An Ion Cyclotron Resonance Study of Ion-Molecule Reactions in Methanol. J. Am. Chem. Soc. 1968, 90(4), 844-851.

44. Mata, R. A.; Costa Cabral, B. J. Structural, Energetic, and Electronic Properties of $(\mathrm{CH} 3 \mathrm{CN}) 2-8$ Clusters by Density Functional Theory. J. Molec. Struct. Theochem. 2004, 673(1/3), 155-164.

45. Lee, S. Y.; Shim, D. N.; Cho, S. G.; Jung, K. H.; Jung, K. W. Proton-Transfer Reactions Within Ionized Methanol Clusters: Mass Spectrometric and Molecular Orbital Studies. J. Mass Spectrom. 1995, 30(7), 969-976.

46. Knoezinger, E.; Beichert, P.; Hermeling, J.; Schrem, O. Matrix Isolation of Acetonitrile Clusters from a Pulsed Supersonic Beam. J. Phys. Chem. 1993, 97, 1324-1331.

47. Plašil, R.; Glosik, J.; Zakouřil, P. Formation and Recombination of Protonated Acetonitrile Clusters. J. Phys. Chem. B. 1999, 32(14), 3575-3583.

48. Marotta, E.; Seraglia, R.; Fabris, F.; Traldi, P. Atmospheric Photoionization Mechanisms. 1. The Case of Acetonitrile. Int. J. Mass Spectrom. 2003, $228,841-849$.

49. Kamel, A. M.; Jeanville, P.; Colizza, K. Mechanism of $[\mathrm{M}+\mathrm{H}]+$ formation in APPI mass spectrometry: Identification of an acetonitrile impurity and possible involvement in the protonation phenomenon. Proceedings of the 54th ASMS Conference on Mass Spectrometry; Seattle, June 2006.

50. Franklin, J. L.; Wada, Y.; Natalis, P.; Hierl, P. M. Ion-Molecule Reactions in Acetonitrile and Propionitrile. J. Phys. Chem. 1966, 70(7), 2353-2361.

51. Stace, A. J.; Shukla, A. K. J. Preferential Solvation of Hydrogen Ions in Mixed Clusters of Water, Methanol, and Ethanol. J. Am. Chem. Soc. 1982, 104(20), 5314-5318.

52. Meot-Ner (Mautner), M. Comparative Stabilities of Cationic and Anionic Hydrogen-Bonded Networks. Mixed Clusters of Water-Methanol. J. Am. Chem. Soc. 1986, 108, 6189.

53. Ahn, D. O.; Lee, S. Computational Study of $\sigma$ - and $\pi$-Type Hydrogen Bonding in Acetonitrile-Water Clusters. Bull. Korean Chem. Soc. 2003, 24(5), 545-546.

54. Deakyne, C. A.; Meot-Ner (Mautner), M.; Campbell, C. L.; Hughes, M. G.; Murphy, S. P. Multicomponent Cluster Ions. 1. The AcetonitrileWater System. J. Chem. Phys. 1986, 90, 4648.

55. Benter, T.; Lorenz, M.; Brockmann, K. J.; Schellenträger, M.; Schiewek, R.; Droste, S.; Constapel, M.; Schmitz, O. J.; Gäb, S. Atmospheric Pressure Laser Ionization (APLI): Current Status, New Applications, and Major Improvements. Proceedings of the 54th ASMS Conference on Mass Spectrometry and Allied Topics; Seattle, June 2006.

56. Pointet, K.; Milliet, A.; Hoyau, S.; Renou-Gonnord, M. F. Proton Affinities of Polybenzoid Aromatic Hydrocarbons and Those with Five-Membered Rings. J. Comput. Chem. 1997, 18(5), 629-637.

57. Lias, S. G.; Bartmess, J. E.; Liebman, J. F.; Holmes, J. L.; Levin, R. D.; Wallard, W. G. Gas-Phase Ion and Neutral Thermochemistry. J. Phys. Chem. Ref. Data 1988, 17, (Suppl. 1).

58. Honma, K.; Sunderlin, L. S.; Armentrout, P. B. Guided-Ion Beam Studies of the Reactions of Protonated Water Clusters, $\mathrm{H}(\mathrm{H} 2 \mathrm{O}) \mathrm{n}+(\mathrm{n}=1$ to 4$)$, with Acetonitrile. J. Chem. Phys. 1993, 99, 1623.

59. Mair, C.; Fedor, J.; Lezius, M.; Scheier, P.; Probst, M.; Herman, Z.; Märk, T. D. Surface-Induced Reactions and Dissociations of Small Acetone, Acetonitrile, and Ethanol Cluster Ions: Competitive Chemical Reactions, Dissociation Mechanisms, and Determination of Dissociation Energy. New J. Phys. 2003, 5, 9.1-9.18. 